\title{
O Silêncio dos Cristais
}

\author{
TERESA SÁ E MELO*
}

\begin{abstract}
À minha Avó materna 1 a primeira mulher livre que conheci.
\end{abstract}

Este texto tem como objectivo divulgar junto dos meus e das minhas colegas, em ciências exactas, o papel das mulheres em investigação, sobretudo o daquelas a quem devemos algumas das mais importantes descobertas científicas, como por exemplo, a da estrutura molecular do benzeno.

Nunca comprendi e ainda hoje constitui para mim um mistério, a razão pela qual não é fácil encontrar em Portugal, um químico ou um físico (de Professor Catedrático a Assistente) $)^{2}$, que tenha conhecimento de que uma descoberta tão fundamental como a da estrutura plana e hexagonal do benzeno foi realizada por uma mulher em 1928 e em 1929: Kathleen Yardley Lonsdale (1903-1971) [1,2].

O trabalho fundamental de Kathleen Yardley (Lonsdale por casamento), incidiu sobre a análise estrutural de algumas centenas de compostos por cristalografia de raios-X.

Definir a estrutura molecular de um cristal era encontrar a solução de um puzzle a três dimensões, com a localização correcta de cada átomo na molécula, após infinitos e fastidiosos cálculos feitos à mão [3].

$\mathrm{O}$ seu artigo " $X$-ray evidence on the structure of the benzene nucleus" é notável pela clareza pedagógica e pela síntese do estado dos conhecimentos da época (anos vinte), no domínio da difracção dos raios-X [2].

Coloca nove perguntas relativas à molécula de benzeno, entre as quais "is the ring hexagonal in shape?" $\mathrm{e}$ "is the ring plane...?", comprovando experimentalmente cada uma das respostas, ao longo das 14 páginas deste artigo [2].

Os grupos de simetria e a estrutura de cada cristal foram compilados em tabelas publicadas em 1924 por Kathleen Lonsdale, em co-autoria com William Thomas Astbury [4]. A representação das respectivas orbitais moleculares, sigma e pi, foi publica- da por esta autora, em 1937 e 1939 $[5,6]$.

Para se ter uma ideia da importância destes dados experimentais, basta dizer que as tabelas cristalográficas, conhecidas por "Astbury-Yardley Tables" [4], constituíram durante largos anos a ferramenta indispensável para os estudos desenvolvidos posteriormente em vários domínios [3], especialmente em biofísica.

Destacamos as descobertas realizadas, com base na técnica de cristalografia dos raios-X, desde o princípio do século até aos anos cinquenta [3]:

- da estrutura hexagonal e planar do benzeno por Kathleen Yardley Lonsdale [1,6].

- da ligação de hidrogénio nos hidróxidos metálicos por J.D.Bernal e Helen D. Megaw [7].

- da estrutura molecular das proteínas e do ADN por W.T. Astbury e Florence Bell (Sawyer por casamento) [8].

- da estrutura molecular em dupla hélice do ADN por Rosalind E. Franklin [9].

- das estruturas moleculares da penincilina, da vitamina B-12, da insulina, etc., por Dorothy Mary Crowfoot (Hodgkin por casamento) $[10]$

Das cinco investigadoras acima sublinhadas, com trabalhos fundamentais e ainda hoje de referência obrigatória, apenas Dorothy Hodgkin obteve o prémio Nobel da Química, em 1964 [10].

Mas não se pense que as mulheres invadiam o domínio da cristalografia no princípio deste século. Olhando para o índice histórico sobre os Fifty Years of X-ray Diffraction (P.P.Ewald), [3] publicado em 1962, verificamos que apenas $3 \%$ eram mulheres, num total de 1200 nomes de pessoas dedicadas à cristalografia.

Em Portugal em 1981, de um total de 20 pessoas a trabalhar neste domínio, 35\% eram mulheres em contraste com os países mais desenvolvidos como os Estados Unidos, onde a percentagem feminina era, no mesmo ano, de $14 \%$ de cristalógrafas num total de 8174 [3].

Esta e outras pequenas histórias

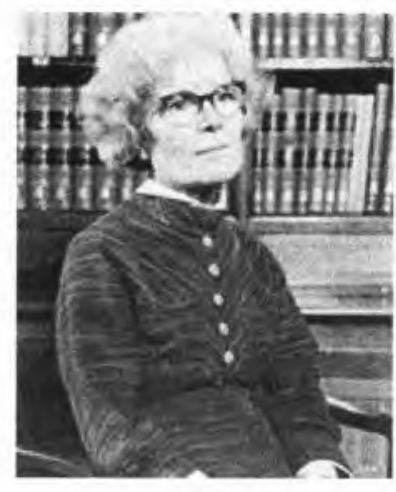

Kathleen Yardley Londsdale (1903-1971) 5

fazem parte de um estudo, com um notável "faro arquelógico", paradoxalmente realizado por americanas, e publicado no livro Women of Science, Righting the Record, em 1990 [3].

Tive dele conhecimento em 1990 em Paris, e a sua leitura incomodou-me duplamente. Incomodou-me, por eu ignorar a existência de algumas investigadoras geniais, em física e em química, apesar da minha formação académica (lic ${ }^{\mathrm{a}} \mathrm{em}$ Química-Física, em Coimbra, em 1973) e da minha cultura científica básica naqueles domínios (Doutorada em Biofísica, em Paris, em 1983). Mas a minha ignorância sobre a existência daquelas cientistas, incomodou-me ainda mais como mulher e como cidadã, sendo eu férrea defensora da participação política e social das mulheres.

De uma forma inconsciente e involuntária estava também a fazer parte do status quo da Academia ${ }^{3}$ e a afastar as mulheres de terem tido, nem que fosse por mera hipótese académica, algum papel na elaboração do saber científico. Pelos vistos o silêncio, além de académico era endémico.

Está fora do âmbito do meu saber, e deste artigo (cuja visão não pretende ser universal), fazer a prova sobre o carácter não neutro das práticas científicas.

Há imensos textos na História das Ciências e na Filosofia das Ciências, cujos saberes evoluíram em época recente no sentido de elucidar esta questão. 


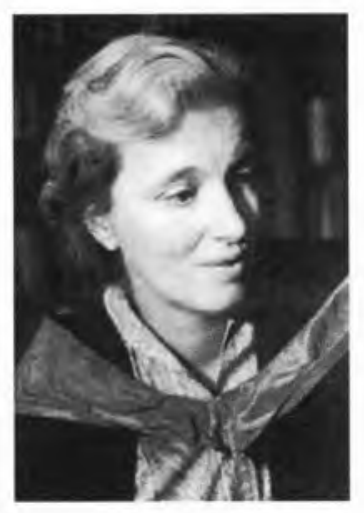

Dorothy Crowfoot Hodgkin (1910-1994) 5

A saber, que a actividade científica e a sua divulgação, tal como qualquer outra actividade humana, não é nem neutra nem assexuada (vide bibliografia).

Porque o silêncio além de académico é endémico, e nunca é demais repeti-lo, um artigo recente destacando "Os 100 Químicos Europeus do Milénio" é disso uma mostra exemplar [11], estando na base da elaboração do presente texto.

Ali podemos ver reproduzida uma lista dos 100 químicos europeus distinguidos pelos seus pares, e elaborada pela Federação das Sociedades Químicas Europeias [11].

Porque os nossos e as nossas colegas, em toda a Europa, vivem e trabalham exactamente naquele contexto de silêncio endémico, os nomes das mais notáveis mulheres de ciência não foram lembrados, nem votados para aquela lista, pelos seus pares.

O meu desejo é que este texto (ligeiramente mais que um simples artigo de divulgação) e outros textos idênticos, possam servir para diminuir o fosso de silêncio a que foram votados os trabalhos pioneiros de algumas das grandes damas das ciências exactas.

Muito embora tenha de reconhecer que, constatar o modo arbitrário como se constroi e divulga o saber científico no meio das ciências ditas exactas, é uma actividade mental extremamente penosa.

É ainda mais penoso porque, conceptualmente, falar de "homens de ciência" é lidar com um conceito "universal e objectivo", ao passo que falar de "mulheres de ciência" é universal e objectivamente considerado tratar-se de um assunto ausente do saber canónico.

No entanto, a Filosofia da Ciência também nos ensina, "que é desta tensão entre o paradigma e a dissonância" de uma outra representação do mundo, que pode surgir a criatividade [12].

Naturalmente que alguns de nós já conheciam o caso gritante do "inocente" e "nobilíssimo" silêncio da Academia nos anos 50, sobre a química-física Rosalind Elsie Franklin (1920-1958) [9,13].

Apesar do seu papel pioneiro na descoberta da estrutura em dupla hélice do ADN, o Nobel foi atribuído em 1962, ao "ambicioso triunvirato" [3] constituído pelos seus colegas Maurice Wilkins, James Watson e Francis Crick [14,15].

Rosalind Franklin morre em 1958 aos 37 anos [3], sem nunca ter sido citada nos trabalhos publicados pelos seus colegas.

Nas três Letters publicadas independentemente no mesmo volume da Nature de 1953 [14] (por ela e por aqueles autores do King's College), apenas o dela fornece a prova experimental para a descoberta da estrutura molecular em dupla hélice do ADN. Os outros autores basearam as suas conclusões nos diagramas de raios-X de Rosalind Franklin, a qual tinha entretanto mudado de laboratório, do King's College para o Birkbeck College de Londres.

De facto, é interessante notar que na Letter de Wilkins acima referida, a proposta para a estrutura molecular do ADN é baseada nos resultados experimentais obtidos nesse ano por Rosalind Franklin [14], e nos de 1938 obtidos por Astbury e Florence Bell [8].

A Letter de Watson e Crick não contém nenhuma evidência experimental para o modelo de dupla hélice proposto [14].

Para se ter uma ideia da "candura" do pensamento de tão brilhantes cientistas basta ler um artigo de James Watson publicado na revista Science em 1985: ..."The person in charge of biology is either a woman or unimportant. They had to put a woman some place. They only had three or four opportunities, so they got someone in here. It's lunacy" [16].

Talvez um menor número de colegas conheça o caso da bióloga Barbara McClintock (1902-1992), que elaborou em 1951 a teoria sobre o transporte dinâmico da informação genética, da célula para o organismo, no milho [17].

Esta teoria sobre os genes de regulação e do genoma como identidade dinâmica, foi descoberta por Barbara McClintock dez anos antes do modelo do genoma proposto por Jacques Monod e François Jacob, no famoso artigo sobre "Genetic regulatory mechanisms in the synthesis of proteins" [18], publicado em 1961.

O trabalho de McClintock só foi reconhecido pela nobilíssima Academia, trinta anos depois, com a atribuição do prémio Nobel em Medicina e Fisiologia em 1983, a uma senhora já muito velhinha com 83 anos.

Mais vale tarde que nunca! $[19,20]$.

Uma questão que nos podemos colocar é a de saber por que razão os nossos colegas da História das Ciências nunca se preocuparam em analisar as relações científicas num casal, mesmo quando era evidente, como no caso de Mileva Maric e

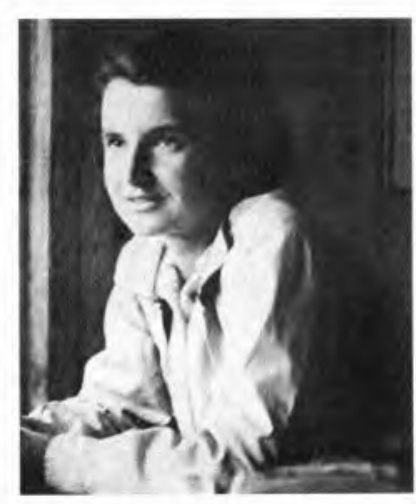

Rosalind Franklin (1920-1958) 5 
Albert Einstein [21], que o nível académico e científico era idêntico e de nível superior em ambos os cônjuges [22].

Só recentemente encontramos estudos como o de Carolyn Merchant sobre "Women, Ecology and the Scientific Revolution", publicado em 1980, onde é analisada a influência inovadora das mulheres em ciência.

Talvez para me aliviar a consciência, elaborei em 1990, um artigo em colaboração com Helena Bastos, publicado na revista Vértice [23] e intitulado "O género da Ciência - Dinâmica de um processo em Portugal". Conseguíamos provar pela primeira vez que as mulheres universitárias, tanto no acesso como no grau de licenciatura, eram não só maioritárias como competitivas no nosso país. Estatisticamente mostrávamos que o seu peso ultrapassava largamente a percentagem feminina da população portuguesa [23].

Mal imaginávamos que alguns anos depois, muitas outras publicações viriam a comprovar o mesmo, desencadeando uma larga controvérsia nos jornais e TV nacionais. Alguns conhecidos analistas chegaram mesmo a defender uma alteração do tipo de ensino ministrado no secundário de forma a contrariar a "natural" e bem conhecida maturidade psicológica das jovens raparigas relativamente aos rapazes.

Apesar do seu peso maioritário e competitivo como licenciadas (muito superior a $60 \%$ ), é notória a existência de filtros de discriminação que travam tanto o ingresso como Assistentes, como o avanço para o topo da carreira académica, como Prof. Associadas e Catedráticas (cerca de 10\%). Este facto é tanto mais relevante quanto se verifica uma capacidade de $100 \%$ para a realização de doutoramentos, em ciências exactas $(30 \%)$, para todas aquelas que conseguiram entrar na carreira académica como Assistentes $(30 \%)$ [23].

Idênticos dados foram recentemente publicados em 1997, para os cursos de informática nos USA, entre 1983 e 1993. No artigo intitu- lado "The incredible shrinking pipeline" (www. mines. edu), a autora Tracy Camp demonstra o mesmo "afunilamento" à medida que se caminha para o doutoramento e para os níveis superiores da carreira académica.

Logo após aquele trabalho, a pergunta que se nos deparava naturalmente era a de saber até que ponto os temas e métodos de investigação assim como as respectivas orientações científicas seriam influenciados [19] por aquela "intempestiva" e recente invasão feminina no feudo masculino dos centros de elaboração do saber. Até hoje não nos foi possível trabalhar aquela questão. Talvez porque incomoda muita gente (a mim em primeiro lugar), talvez porque o silêncio faz parte da sabedoria ancestral das mulheres, ou talvez porque já atingimos aquela sabedoria da meia-idade que nos faz ter a intuição do poeta que canta uma verdade indizível.

Em Física, o mais famoso caso silenciado pela Academia diz respeito à descoberta do processo da cisão nuclear realizado por Lise Meitner (1878-1968), no decorrer dos anos trinta, em colaboração com o seu sobrinho Otto Frisch [24].

Apesar daquele trabalho pioneiro, o prémio Nobel da Química foi atribuído, em 1944, a Otto Hahn pela mesma descoberta! [25,26,27] A Europa estava em guerra e Lise Meitner, por ser judia, "desapareceu" por uns anos dos laboratórios germânicos.

Foi ela quem descobriu e classificou dois novos emissores beta na série do rádio. Estabeleceu a relação entre os raios beta e gama da desintegração radioactiva e observou os primeiros positrões a partir dos raios gama [3].

O seu trabalho mais conhecido, intitulado "Desintegration of uranium by neutrons; a new type of nuclear reactions", foi publicado na Nature em 1939 [28].

Deu o nome ao elemento transuraniano Meitnerium, descobrindo também o elemento 91, Protactinium, com Otto Hahn.

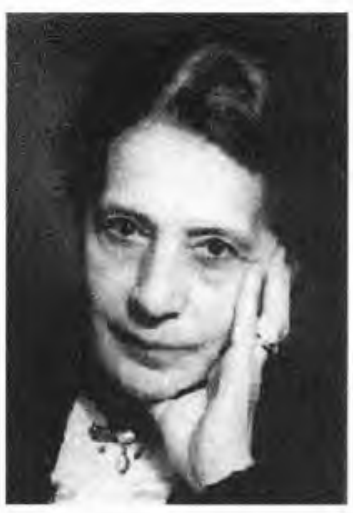

Lise Meitner (1878-1968)6

O conceito de cisão ("fission") foi introduzido em analogia com o termo utilizado na divisão celular de uma bactéria, por sugestão do bioquímico americano William A. Arnold [29].

Ironicamente, Lise Meitner foi agraciada pela Academia alemã com o prémio Otto Hahn em 1954!

Estamos a falar de uma grande dama da física que durante décadas foi a colega e companheira de discussões de Max Planck, Stefan Meyer, Albert Einstein, Niels Bohr, Walther Nernst, Heinrich Hertz e Erwin Schrödinger [3].

Outra física famosa é Maria Goeppert-(Mayer por casamento), que viveu no período de 1906 a 1972. Obteve o seu doutoramento em Física teórica em 1930 em Gottingen, aos 24 anos, com uma tese sobre "On elementary processes with two photon jumping". Casou com o químico americano Joseph Mayer e instalou-se nos USA durante a $2^{\text {a }}$ guerra mundial.

Recebeu o prémio Nobel da Física em 1963 (com J.Jensen), por ter descoberto o modelo nuclear em camadas [30] e ter descrito o acoplamento spin-órbita [31,32].

Os seus trabalhos, nomeadamente sobre os níveis electrónicos de mais baixa energia do benzeno e o livro sobre mecânica estatística, são ainda hoje citados, e constituem livros de texto no domínio [3].

Nenhum e nenhuma de nós tem o direito de ignorar as dificulda- 
des que se apresentavam às mulheres em ciência e fazer de conta que não existem mentalidades como as de um físico tão famoso como Max Planck (1858-1947, prémio Nobel em 1918).

Ele afirmava em 1897: "If a woman has a special gift for the tasks of theoretical physics...I do not think it right, both personally and impersonally, to refuse her the chance and means of studying for reasons of principle. On the other hand, I must keep to the fact that such a case must always be regarded just as an exception. Generally, it cannot be emphasized enough that nature herself prescribes to a woman her function as mother and housewife" [27].

$\mathrm{O}$ que fica patente neste discurso do eminente Max Planck é uma prática científica instituída como dogma "natural". A saber, que a associação mulher-cientista contém em si dois conceitos antagónicos.

Contava Lise Meitner na sua conferência em 1959 sobre "The status of women in the professions" [33]: "Era meu hábito assinar os artigos apenas com o meu apelido. Um dia, o editor da revista recebeu uma carta em que um dos coordenadores da prestigiada Enciclopédia Brockhaus pedia o meu endereço, dado que pretendia que eu escrevesse um artigo sobre radioactividade.

Ao responder, o meu editor revelou que eu era mulher. O responsável da Brockhaus ripostou, agora bastante irritado, que era impensável incluir na sua enciclopédia um artigo escrito por uma mulher!" [29]

Lise Meitner continuou relatando a sua vida de cientista: "O grande químico orgânico Emil Fischer foi relutante em deixar-me trabalhar no seu laboratório com Otto Hahn. Proibiu-me mesmo de entrar nas salas onde Hahn e outros colegas masculinos realizavam as investigações experimentais...Fui então falar com Fischer e ele disse-me que a sua relutância em aceitar mulheres nas suas aulas tinha por origem a preocupação de que o cabelo exótico de uma aluna (russa) pegasse fogo quando estivesse a trabalhar com o bico de Bunsen!...

Em consequência desta proibição, não pude iniciar os meus estudos de ra- dioquímica durante vários anos" [3,29]. Mas não foi a única impedida de trabalhar em ciência. Lise Meitner conta ainda que o grande matemático David Hilbert, ao tentar obter da Faculdade de Gottingen autorização para a sua assistente, Emily Amalie Noether (1882-1935), cientista de talento, poder candidatar-se à privat dozent para integrar os corpos da Faculdade, encontrou tanta hostilidade que, indignado, exclamou: "Mas meus senhores, uma Faculdade não é propriamente uma piscina!" $[3,29]$.

Note-se que Emmy Noether, filha do matemático Max Noether, é a criadora da álgebra moderna tendo introduzido a teoria dos grupos (anéis), hoje conhecida pelo seu nome, no artigo publicado em 1921 "Idealtheorie in Ringbereichen". Einstein referia-se a ela, em carta endereçada a Hilbert, como a de uma pessoa com "um profundo pensamento matemático". De facto, o trabalho de Emmy Noether sobre a teoria das invariantes (Invariante Variationsprobleme, 1918) conduziu às formulações conceptuais da teoria geral da relatividade de Einstein. Esta é uma questão recente e vem referida nos trabalhos de história da matemática de J.J. O'Connor e E.F. Robertson, em www-history.mcs.st-andrews.ac.uk.

$O$ recente livro com as cartas da filha de Galileo ao pai [34] é rico em fornecer-nos o contexto dos homens de ciência daquela época (1564-1642 ), ao qual voltarei mais à frente.

A sua leitura fez-me reflectir sobre o paralelismo entre os dogmas da Igreja Católica e os paradigmas em Ciência, conceito introduzido em 1962 por Thomas Kuhn, no seu conhecido livro sobre "A estrutura das revoluções científicas" [35].

É o próprio Kuhn que nos explica a mudança conceptual do pensamento científico moderno, no prefácio da sua obra posterior, "A tensão essencial" [36], publicada em 1977:

"Logo depois de ter completado um primeiro esboço em 1961, de A estrutura (das revoluçôes científicas), escrevi...um ensaio sob o título A função do dogma na investigação científica, publicado em 1963. Comparando-o com A tensão essencial (de 1977), torna-se claro e imediato o alargamento da minha noção de paradigma" [28]. E acrescenta: "De algum modo, é uma reminiscência da posição familiar (posição filosófica tradicional no sec. XVII) que considera a teoria ptolomaica,...ou a teoria calórica como meros erros, confusóes ou dogmatismos que uma ciência mais liberal ou inteligente podia ter evitado desde o início" [36].

Daí a mudança conceptual de dogma para paradigma. E já agora, porque não paradogma 4 ?

Os bons Espíritos, os Eleitos pela Razão, intelectualmente recusaram sempre ter que admitir que a Ciência, tal como a Igreja, também tinha os seus dogmas, as suas "regras de jogo", ditas objectivas e universais.

De facto, todos nós acreditamos piamente que tendo a ciência um carácter universal por definição, baseado na prova e independente do sujeito teorizante, ela se encontra forçosamente isenta dos pecados profanos, do comum dos mortais.

Intelectualmente é-nos difícil admitir que o saber adquirido através de práticas científicas fortemente sexuadas está longe de ser universal, neutro ou assexuado.

Porque, como afirmam algumas investigadoras, se não se pode dizer neutro, a conclusão imediata é que é arbitrário [19,22].

A inocente crença de que a universalidade é um conceito realista constitui o ícone da Academia, o seu credo, o seu direito romano [37].

Não é pois de espantar que um dogma tão "natural" como o da existência de uma contradição entre ser mulher e ser cientista não tenha sido completamente refutado. De facto, ser mulher e ser cientista, ainda hoje se situa ao nível da "anomalia" em ciência.

No dizer de Thomas Kuhn, "há factos cuja existência serve, não para contradizer ou refutar o paradigma, mas para serem considerados como anomalias" [12].

A constatação de que é no pró- 
prio interior da comunidade científica que se encontram os maiores entraves à difusão das novas ideias $\mathrm{e}$ conhecimentos foi largamente divulgada por Thomas Kuhn, Alexandre Koyré, Gaston Bachelard e recentemente Isabelle Stengers. No nosso país, há uma excelente contribuição para esta "anomalia", no livro de Sebastião Formosinho, sobre os entraves da Academia ao aparecimento de um novo modelo teórico por ele inventado [38].

Para provar como as nossas velhas Universidades europeias se sentem tão protegidas e confortadas nas suas doutrinas establecidas basta dar o exemplo de Galileo Galilei (1564-1642).

As pessoas em geral e os cientistas em particular só têm deste caso a memória de um processo obscurantista aplicado pelo Santo Ofício, o qual colocou o Diálogo [39] de Galileo, publicado em 1632, no index dos livros proibidos até 1835. A primeira tradução do seu livro "Discorsi e demonstrazioni Matematiche intorno a due nuove scien$z e^{\prime \prime}$, foi realizada em 1638, por Louis Elzevier (Leiden) ainda em vida de Galileo [34].

No entanto, poucos o sabem e muitos se esquecem, que a difusão desta obra e a sua introdução como livro de texto nas Universidades foi realizada apenas 200 anos [34] depois da $1^{a}$ visão "celestial" do mundo!

Também é verdade que a Universidade de Pisa, que teve o privilégio de contar com Galileo entre os seus "lentes" em 1589, o agraciou com um grau honorífico, apenas em 1892, [34] i.e, 300 anos depois de ter usufruído do seu magistério!

Claro que a Igreja Católica Romana só condescendeu em reconhecer a importância daquele pensamento brilhante e "transcendente" em 1992, i.e 360 anos depois da publicação do Diálogo.

Poderíamos até fazer um pequeno exercício de cálculo da velocidade de refutação de um paradigma em ciência.
Volto a frisar que é este último exemplo, o do obscurantismo intelectual "dos outros", ou da dita "posição filosófica tradicional pouco inteligente", que nos conforta ideologicamente nas verdades "paradigmáticas" do nosso Templo científico.

Conceptualmente construímos o templo ideológico onde nos movemos através da ideia de uma ciência em abstracto, edificada ao longo dos séculos de forma universal, com base na existência de prova.

A existência de prova científica cai por terra e não é válida durante 200 anos, como vimos no caso de Galileo.

Por outro lado, o sujeito teorizante está fortemente implicado com a sua mentalidade, cultura, vícios e preconceitos "naturais", como acabámos de mostrar.

Neste contexto, o saber científico de Kathleen Yardley Londsdale é tido como uma provocação para a Razão dos Eleitos, um conhecimento não sancionado pela Academia. Assim, ela foi afastada dos livros canónicos e colocada no esquecimento, na segunda fila, atrás dos eleitos seus contemporâneos.

Parafraseando George Steiner, diriamos que o seu epitáfio no túmulo da esperança seria "Lamento, mas é tarde demais!" [37]

Será que acabarão por existir sábios nossos contemporâneos que, tal como René Descartes (1596-1650) e Pierre de Fermat (1608-1665) o fizeram [34], se colocarão solidariamente na defesa de Galileo Galilei e das suas "inenquadráveis" descendentes?

Sobre o desenvolvimento da Lógica, Francis Bacon (1561-1626) afirmava em 1620, que ela servia mais para corroborar os erros do senso comum do que para atingir a verdade (citado por Sebastião Formosinho).

Mas voltando à lógica imposta pelo dogma "natural" sobre o qual me debruço neste texto, i. e, a contradição entre ser mulher e ser cientista.

Pessoas tão eminentes como Max Planck (1858-1947) não poderiam nem deveriam fazer a economia de uma cultura científica. Tão brilhante cientista deveria pelo menos saber da existência das mulheres que divulgaram o saber científico na Europa, nos séculos XVIII e XIX.

Por exemplo, a obra científica mais notável dos finais do sec. XVII, o tratado Philosophiae Naturalis Principia Mathematica de Isaac Newton, publicado em 1687, foi introduzida em França por uma mulher, Émilie de Breteuil (1706-1749), Marquise de Chatelêt em 1759. Foi ela que traduziu e explicou esta obra aos leigos, constituindo aliás até hoje, a única tradução existente em França [40].

A propósito deste trabalho, Voltaire (1694-1778) comentou: "On a des prodiges: l'un, que Newton ait fait cet Ouvrage; l'autre qu'une Dame l'ait traduit et l'ait éclairci" [40].

Note-se que Newton (1642$-1727)$, nasceu no ano da morte de Galileo [34].

Sabemos recentemente que nos séculos XVII e XVIII, entre as mulheres consideradas "sábias", existiam mais científicas que literárias versadas nas línguas eruditas, o grego e o latim, visto naquela época lhes ser vedada a entrada nas instituições académicas [40].

Mais à frente descrevo o caso de uma portuguesa do séc. XVI, conhecedora das teses de Aristóteles.

Há várias mulheres que elaboraram ou popularizaram os conhecimentos da física e astronomia nos séculos passados [41]. No séc. XIX temos o exemplo de Mary Sommerville (1780-1872), que publicou "On the connexion of the Physical Sciences" em 1834. É citada por Thomas S. Kuhn na obra acima referida [36], por afirmar:

"O progresso da ciência moderna, especialmente nos últimos cinco anos, foi notável devido à tendência para unir ramos separados da ciência. Existe um tal elo de união que não se pode atingir competência em nenhum dos ramos, sem se ter conhecimentos dos outros".

Também no séc. XIX, Jane Haldemond Marcet (1769-1858) popularizou a química no seu livro "Conversations on Chemistry", publica- 
do em 1805. Este livro que teve 16 edições até 1853, revelou ao muito jovem Michael Faraday, o princípio do conhecimento das coisas naturais, como o próprio afirmou [3].

Parece haver um enorme fosso entre quem adquire o saber e quem o representa. Será um vício intelectual inerente apenas aos séculos passados?

É de notar que esta forma de silenciar o trabalho pioneiro e histórico dos pares femininos não é apanágio exclusivo dos fellows masculinos em Ciência!

Na lecture apresentada por Dorothy Hodgkin (1910-1994), quando ela recebeu o prémio Nobel da Química em 1964, pode ler-se:"...the crystals were grown under the watchful eyes of Kathleen Lonsdale, who brought them to me from London" [10].

No entanto, na bibliografia desta sua lecture com 28 referências, não consta nenhum artigo da famosa Dame Kathleen Lonsdale, Fellow da Royal Society de Londres desde 1945.

Note-se que Kathleen Londsdale não era propriamente a amiga mais velha que colaborava "maternalmente" no trabalho de fazer crescer os cristais para as experiências da jovem Dorothy Hodgkin. Kathleen Londsdale trabalhou até morrer em 1971, criando novos cristais, alguns com o seu nome (Lonsdalite) e publicando os seus últimos artigos em 1968 e 1971.

Finalmente, Dorothy Hodgkin dedicou-lhe um artigo de memória biográfica em 1975 [3].

Em química, grande parte das técnicas experimentais ainda hoje utilizadas foram descobertas por mulheres. Actualmente, a maioria dos nossos e das nossas colegas de ciências exactas não têm disso conhecimento.

A seguir indico alguns casos que foram retirados do livro Women of Science [3], (salvo quando indicado), não sendo a lista exaustiva:

Agnes Pockels (1862-1935) foi a fundadora da química das superfícies e inventou "a method of extending or reducing the surface area of water by means of a wire or metal strip placed over it", publicado na Nature em 1891 e 1892 [42].

Yulua Vsevolodovna Lermontova (1846-1919) desenhou o equipamento para a separação, que realizou pela $1^{\text {a }}$ vez em Moscovo, dos hidrocarbonetos do petróleo utilizando catalizadores metálicos.

Marie Semenova Schraiber (1904-) inventou a cromatografia em camada fina TLC, em 1938.

Emma Perry Carr (1880. -1972) compilou o $1^{\circ}$ catálogo dos espectros de absorção de hidrocarbonetos, purificados no seu grupo de trabalho, e tidos como referência padrão pelo American Petroleum Institute, a partir dos anos trinta.

Maude Menten (1879-1960) é co-autora com Leonor Michaelis (1875-1940) da descoberta em 1913, da famosa equação Michaelis-Menten para a análise da velocidade das reacções das enzimas com os substratos. Inventou em 1944, um teste bioquímico para a detecção da enzima fosfatase alcalina, no fígado.

Erika Cremer (1900-) é a fundadora da cromatografia gasosa. Desenhou o equipamento e desenvolveu a técnica de cromatografia gasosa, enviada para publicação em 1945. Descobriu ainda novas substâncias para uma detecção selectiva.

Gertrude B. Ellion (1918- ) sintetizou os fármacos e estabeleceu os protocolos clínicos ainda hoje utilizados no tratamento da hiperuricémia e da leucemia, obtendo o prémio Nobel em Medicina, em 1988, juntamente com o seu colega George Hitching.

Mary Osborn que introduziu o uso do gel de SDS para medir o peso molecular das proteínas. O seu artigo em conjunto com Klaus Weber (J.Biol.Chem. 244,4406, 1969) foi o $4^{\circ}$ artigo mais citado durante largas dezenas de anos, até 1988 [43].

A melhor forma de silenciar e esquecer é-nos fornecida exemplarmente pelos livros de texto, nomeadamente pelas Enciclopédias de Ciência e Tecnologia, como por exemplo a de Isaac Asimov
(1976). Aí são descritos 1187 "homens de ciência" e apenas 10 "mulheres de ciência." [3] Destas dez, 5 são Prémio Nobel, em contraste com os 1187 onde não há $50 \%$ com o mesmo nobilíssimo saber. Qual foi o critério para a escolha desta representação do saber científico?

Em Portugal, das letras às ciências, salvo raras excepções, pouco se conhece sobre a actividade científica das mulheres, do século passado até hoje.

No entanto, desde o século passado muitas foram as que frequentaram cursos em ciências exactas nas duas Universidades, de Coimbra e Lisboa, e que obtiveram os seus doutoraramentos no início deste século, publicando os trabalhos em revistas internacionais, pelo menos a partir de 1922.

De facto, inúmeras mulheres portuguesas realizaram trabalhos em ciências exactas, no início do século, cujo impacto e peso inovador está ainda longe de ser avaliado.

Era importante aceder aos originais dos artigos por elas publicados, através das instituições científicas portuguesas onde trabalharam. Gostaria de o poder realizar se para isso tiver algum engenho e arte.

A seguir indico alguns casos, do princípio do século, enumerando simplesmente os nomes que retirei de duas fontes (salvo quando indicado) $[44,45]$ :

A $1^{\text {a }}$ mulher na Universidade de Coimbra no séc. XVI [46] a ter o seu grau de Bacharel em Filosofia foi a alentejana Públia Hortênsia de Castro (1548-1595).

A história é relatada como se se tratasse de uma lenda. Vestiu-se "de rapaz sem que ninguém o suspeitasse, debaixo da vigilância e proteç̧ão de seu irmão mais velho que também estudava", frequentou os cursos de philosofia e theologia em Coimbra (e em Évora). "Pronuncia o discurso de graduação em latim em que era versada...apesar de nem todos o perceberem. conseguiu transmitir ao auditório,... pela agudeza de inteligência, o verdadeiro significado das suas ideias" [47].

Dizia dela o douto André de 
Resende a Bartolomeu de Frias: " $A$ coisa mais para ver foi Públia Hortênsia, rapariga de dezassete anos, tão versada nas máximas de Aristóteles que, disputando em conclusões públicas com muitos sábios, não achou argumento por mais caviloso que não resolvesse com a maior prontidão, e não menor graça" [48].

Existirão documentos da autoria desta jovem "sábia"?

Dos registos da Universidade de Coimbra [45] apenas consta o nome de Domitilla Hormizinda Miranda de Carvalho como sendo a $1^{\text {a }}$ mulher inscrita no curso de Matemática e no curso de Filosofia em 1891. Durante cinco anos foi a única mulher na Universidade, terminando aquelas duas licenciaturas 1898 e em 1895, respectivamente. Em 1899 matriculou-se ainda no curso de Medicina vindo a finalizar a sua terceira licenciatura em 1904/5.

Temos ainda o exemplo de duas farmacêuticas, Esther Nogueira e Elvira Magro, Assistentes da Faculdade de Farmácia de Lisboa, autoras dos artigos "Considerações sobre alguns processos de depuração das águas destinadas à alimentação" e "Aguamento dos leites - métodos gerais de pesquisa - a determinação da densidade do sôro, factor base para a apreciação", publicados nas Actas do $1^{\circ}$ Congresso Nacional de Farmácia, pp.198-207 e pp.208-211 de 1927, respectivamente [49].

É de notar que as duas conferências das referidas autoras foram lidas ao Congresso pelo Dr. Pinheiro Nunes! [49]

Sara Benoliel, naturalizada portuguesa em 1928, licenciada em Medicina com uma tese de doutoramento em 1926 sobre "Modificações do líquido céfalo-raquidiano na meningite tuberculosa".

É autora de várias publicações em revistas médicas sobre a luta contra a tuberculose, sobre a vacina preventiva contra a difteria e sobre pediatria e puericultura, pelo menos até 1935.

Judite Belo, licenciada em Físico-Químicas, investigadora em Biologia no IPO, publicou vários artigos entre eles "Teoria e significado das medições do pH" e "Reaç̧ões elementares singulares em Biologia".
Matilde Bensaude, doutorada em Ciências Biológicas em 1918 em Paris, investigadora do Instituto Bento da Rocha Cabral. É autora de numerosas publicações sobre fitopatologias nas culturas frutículas em Portugal, entre 1918 e 1929.

Amélia Bacelar, licenciada em Ciências Naturais em 1920 e autora de diversas publicações internacionais no domínio da zoologia entre 1927 e 1932.

Ainda poderemos frisar o caso de Branca Edmée Marques, licenciada em Físico-Químicas, Assistente da Faculdade de Ciências de Lisboa desde 1924. Obteve o doutoramento em 1935, com trabalhos desenvolvidos em colaboração com Mme Curie, no Instituto do Rádio de Paris, entre 1931 e 1935. É autora de diversas publicações sobre o fraccionamento dos sais de bário, pelo menos até 1939.

E ainda, Lídia Salgueiro e Marieta da Silveira, ambas licenciadas em Físico-Química em 1941 e ambas Doutoradas em 1945.

Seomara da Costa Primo, doutorou-se em Ciências Biológicas em 1942 e publicou os seus trabalhos científicos a partir de 1927 até 1943.

Branca Fernandes Rumina, licenciada em Medicina (Oftalmologista), com pulicações científicas desde 1922 até 1942.

Maria Valadares, licenciada em Ciências Biológicas com trabalhos de investigação em genética e publicações internacionais entre 1937 e 1946

Este texto coloca algumas objecções e interrogações "não de ordem filosófica mas humana", sobre como se constroem alguns "símbolos canónicos" em Ciência. Seria necessária alguma intuição poética para vos assegurar o essencial, que não foi aqui descrito.

\footnotetext{
* Centro de Química-Física Molecular, Complexo l. Instituto Superior Técnico e-mail: teresasamelo@ist.utl.pt
}

\section{NOTAS:}

1 Maria Amélia Medina Tavares de Almeida Carvalho Macedo.

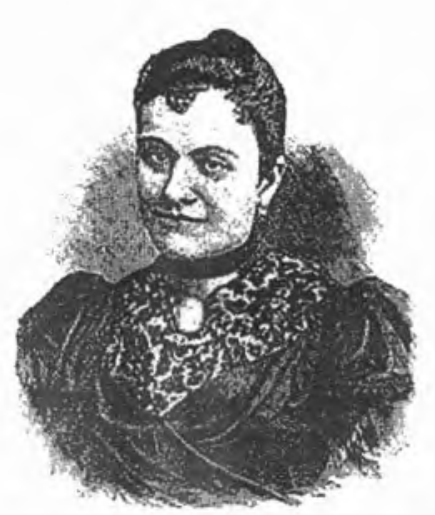

Domitilia Hormesinda Miranda de Carvalho?

2. Alguma eventual excepção serve para confirmar a regra.

3 Designação referida à escola de Platão em Atenas.

4 Este termo foi-me sugerido pela minha colega, Ana Maria Botelho do Rego, no decorrer das nossas conversas sobre os dogmas em ciência.

Imagens reproduzidas com autorização a partir de "Contributions of 20th Century Women to Physics." CWP, no endereço http://www. physics.ucla.edu/ cwp.

Imagem reproduzida com autorização. Ref. Meitner, Lise, A4, AIP Emilio Segrè Visual Archives, Herzfeld Collection.

(Cortesia da Dra. Maria Reynolds de Sousa, CIDM).

\section{BIBLIOGRAFIA}

1. Kathleen Yardley "The structure of the benzene ring" Nature, 122, 810, 1928.

2. Kathleen Yardley "X-ray evidence of the structure of the benzene ring" Trans. Faraday Soc. 25, 352 $366,1929$.

3. "Women of Science, Righting the Record" Ed G. Kass-Simon and Patricia Farnes, Ass.Ed. Deborah Nash Indiana University Press, 1990.

4. W.T.Astbury and Kathleen Londsdale "Tabulated data for the examination of the 230 space groups by homogeneous X-rays" Philosophical Transactions of the Royal Society A224, 221, 1924

5. Kathleen Londsdale "Magnetic anisotropy and electronic structure of aromatic molecules" Proc. Roy. Soc. London A159, 149-161, 1937.

6. Kathleen Londsdale "Diamagnetic anisotropy of organic molecules" Proc. Roy, Soc, London A171, $541-568,1939$

7. Proc.Roy. Soc. London, A151, 384-40, 1935.

8. Cold Spring Harbor Symp. 6, 109, 1938.

9. Rosalind E.Franklin and R.G.Gosling "Evidence 
for 2-chain helix in crystalline of sodium deoxyribonucleate" Nature, 172, 156, 1953 (e ainda dos mesmos autores em Nature 171, 740 1953).

10. Dorothy Crowfoot Hodgkin "The X-ray analysis of complicated molecules" Nobel lecture, Stockholm, Sweden 11 Dec. 1964 Science 150, 979-988, 1965.

11. Colin Russel, "Os químicos favoritos da Europa" Química, $\mathrm{n}^{\circ}$ 76, 48, 2000.

12. Bruno Jarroson, "Invitation à la Philosophie des Sciences" Ed. Seuil, 1992.

13. S.Sayre, "Rosalind Franklin and DNA" W.W.Norton \& Co, N.Y. 1975.

14. Watson J.D. and F.H.C. Crick Nature 171, 737 1953 Wilkins M.H.F., A.R.Stocks and H.R.Wilson Nature 171, 739, 1953 Franklin Rosalind E. and R.G.Gosling Nature 171, 741, 1953

15. F.H.C. Crick and J.D.Watson Proc.Roy Soc. A $223,80,1954$

16. Science $12, \mathbf{1 6 0}, 1985$.

17. Cold Spring Harbor Symp. Quant. Biol. 16:1347, 1951.

18. J.Mol.Biol.3, 318-356, 1961.

19. "Feminist approches to science", Ed. Ruth Bleir Pergamon Press, 1986.

20. Evelyn Fox Keller, "L'intuition du vivant. La vie et I'oeuvre de Barbara McClintock" Paris, Tierce 1983.

21. Albert Einstein 1879-1955, prémio Nobel da Física em 1921.

22. "Le sexe des sciences", Autrement, $n^{0} 6$, Oct.1992.

23. Teresa Sá e Melo e Helena Bastos “O género da Ciência- Dinâmica de um processo em Portugal" Vértice, $n^{\circ} 29,55-59$, Agosto 1990.

24. Nature, vol.143, 471, 1939 Nature, vol.143, $637,1939$.

25. Patricia Rife, "Lise Meitner and the dawn of nuclear age" Birkhauser, 1999.

26. Ruth Sime, "Lise Meitner: a life in Physics" Unv. California Press, 1996.

27. Helge Kragh, Physics World, pp.45, March 2000

28. Lise Meitner and "Desintegration of uranium by neutrons; a new type of nuclear reactions" Nature, vol.143, 239, 1939.

29. A.M.Nunes dos Santos, Maria Amália Bento e Christopher Auretta, "Mulheres na Ciência" Gradiva, Lisboa 1991.

30. "The shell model" Science 145, 999-1006, 1964

31. "Nuclear configurations in the spin-orbit coupling model I:empirical evidence" Phys.Rev. 78, 16-21, 1959.

32. "Nuclear configurations in the spin-orbit coupling model II:theoretical considerations" Phys.Rev. 22-23, 1959.
33. Physics Today, 13, 17 Aug. 1960.

34. Dava Sobel, "Gallileo's daughter" Fourth Estate, London 1999.

35. Thomas S. Kuhn "La structure des révolutions scientifiques" Flammarion 1972 (1"edição USA ,1962).

36. Thomas S. Kuhn "A tensão essencial" Edições 70, Lisboa 1989

37. George Steiner, "Errata", Gallimard 1998.

38. Sebastião Formosinho "Nos bastidores da Ciência" - Resistências dos cientistas à inovação científica" Gradiva, 1988.

39. Galileo Galilei, "I Dialoghi Sui massimi sistemi Tolemaico e Copernicano", Milano, Edvardo Sousogno, 1877 (408 pag.).

40. Jeanne Peiffer, "Le sexe des sciences" Autrement, $n^{2} 6$, Oct.1992.

41. Caroline L. Hezenberg, "Women Scientists from Antiquity to the Present: an Index", West Cornwall: Locust Hill Press, 1986.
42. Nature 43, 437, 1891 Nature 46, 418, 1892.

43. "European Handbook of Women experts in Science, Engineering and Technology", WITEC 1996.

44. "Livros Escritos por Mulheres", Catálogo da exposição organizado pelo Conselho Nacional das Mulheres Portuguesas Ed. Soc.Nac.Belas Artes, Lisboa 1947

45. Joaquim Ferreira Gomes “A mulher na Universidade de Coimbra" Livraria Almedina, Coimbra 1987

46. Diogo Manuel Ayres de Azevedo"Portugal ilustrado pelo sexo feminino" (citado por M"Regina Tavares da Silva, CCF n²1, 1987).

47. Eduardo Schwalbach Lucci "A mulher portuguesa" Lélo \& Irmãos, Porto 1916.

48. Santos Guerra "O valor da mulher portuguesa d'aquém e d'além mar" Lisboa 1955.

49. João Rui C.R. Pita " $1{ }^{\circ}$ Congresso Nacional de Farmácia-60 anos depois" Bol. Fac. Farm. Coimbra, 10, 59-82, 1986.

\section{KCENIKK- TECH}

\section{Kromatografia + EspeKtroscopia}

\section{CROMATOGRAFIA: HRGC / HPLC ESPECTROSCOPIA/ESPECTROMETRIA ENGENHARIA EQUIPAMENTOS DE LABORATÓRIO PREPARAÇÃO DE AMOSTRAS CIÊNCIA DE MATERIAIS/VÁCUO}

Konik-Tech, S.A.

Rua Prof. Veiga Ferreira, 6B 1600 Lisboa

Telef. 217573547

Fax. 217573485

E-mail: lisboa@konik-group.com

Vendas: sales@konik-group.com Marketing: marketing@konik-group.com Serviço Técnico: SAT@konik-group.com www.konik-group.com 
$S T V$ - Equipamentos para a Indústria e Laboratórios, Lda

\section{EQUIPAMENTO DE VÁCUO}

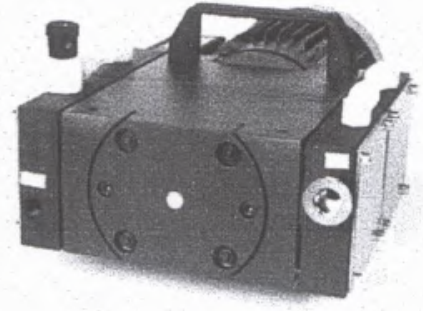

Sistemas de deposição térmica e de Sputtering

Detectores de fugas

Manipuladores de amostras

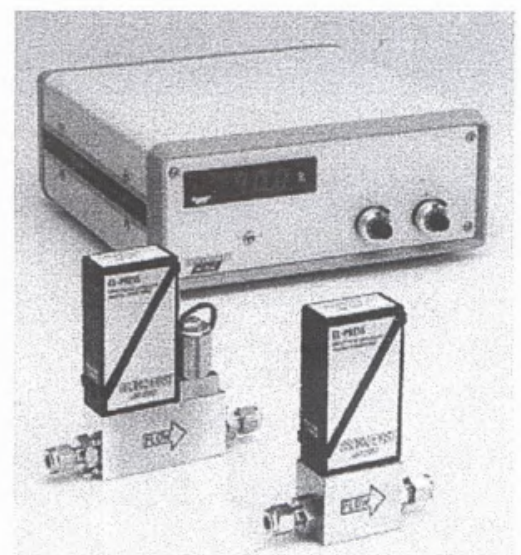

Bombas de membrana Bombas rotativas a óleo Bombas difusoras Bombas Turbomoleculares Bombas Roots Bombas quimicas secas Bombas lónicas

Válvulas, vedantes, flanges,óleos e "greases".

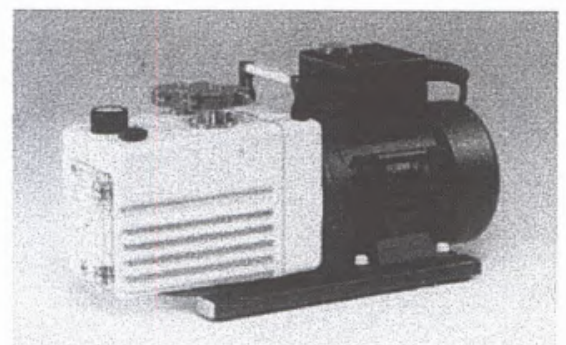

Medidores/controladores de vácuo:

- Piezoeléctricos, Piranis, Pennings, Capacitivos (Baratron) e Ion gauges. Medidores/controladores de Fluxo e Massa.

LIOFILIZADORES

\section{OUTROS EQUIPAMENTOS}

Balanças Analíticas. Banhos de Ultrasons. Banhos Termostáticos. Recirculadores. Geradores de Gases. Manoredutores. Fluxímetros. Manoredutores e Reguladores de Pressão. Compressores Silenciosos. Compressores Secos. Válvulas, Tubos e Conecções para Fluidos.

$S T V$ - Equipamentos para a Indústria e Laboratórios, Lda

Casal da Serra, lote 103 - loja Esq.- 2625-082 Póvoa Santa Iria Tel. 01- 9563007 